\title{
Association between small for gestational age and risk of autism spectrum disorders: a meta-analysis
}

\author{
Ensiyeh Jenabi, $\mathrm{PhD}^{1}$, Saeid Bashirian, $\mathrm{PhD}^{2}$, Zahra Asali, $\mathrm{MSc}^{3}$, Mahdieh Seyedi, MSc ${ }^{1}$ \\ ${ }^{1}$ Autism Spectrum Disorders Research Center, Hamadan University of Medical Sciences, Hamadan, Iran; ${ }^{2}$ Social Determinants of Health Research Center, Hamadan \\ University of Medical Sciences, Hamadan, Iran; ${ }^{3}$ Department of Midwifery, Tuyserkan Branch, Islamic Azad University, Tuyserkan, Iran
}

\begin{abstract}
Background: The relationship between small for gestational age (SGA) and autism spectrum disorders (ASDs) remains
\end{abstract} unknown.

Purpose: This meta-analysis aimed to investigate the relationship between SGA and the risk of ASD.

Methods: We searched PubMed, Web of Science, and Scopus databases from inception to November 2020. The heterogeneity across studies was explored using the $I^{2}$ statistic. The possibility of publication bias was assessed using Begg test. The results were reported using the odds ratio (OR) and 95\% confidence interval (CI) using a random-effects model.

Results: The literature search yielded 824 articles with 8,752,138 participants. We assessed the association between SGA and the risk of ASD in cohort and case-control studies. Based on the random-effects model, compared with SGA, the estimated OR of the risk of ASD was 1.17 (95\% CI, 1.09-1.24). Therefore, there was a significant association between SGA and the risk of ASD.

Conclusion: Based on OR reports in epidemiological studies, we showed that SGA is a risk factor for and can increase the risk of ASD. The association between SGA and ASD risk has further relevance to the current public health emphasis on appropriate prepregnancy weight and pregnancy weight gain.

Key words: Autism spectrum disorder, Meta-analysis, Small for gestational age

\section{Key message}

- The relationship between small for gestational age (SGA) and autism spectrum disorders (ASDs) and remains conflicting.

- We showed based on odds ratio reports in epidemiological studies that SGA can increase the risk of ASD and SGA is a risk factor for ASD.

- The association between SGA and the risk of ASD has further momentum to the current public health emphasis on appropriate prepregnancy weight and weight gain during pregnancy.

\section{Introduction}

Autism spectrum disorder (ASD) is a brain-based neurodevelopmental disorder characterized by deficits in communication skills, social interactions, and interests as well as stereotypical behaviors. Children with ASD also have abnormalities in cognitive functioning, learning, attention, and sensory processing. This condition is typically present in early childhood.1) Studies show that the prevalence of autism differs from one in every 132 to one in every 68 individuals. ${ }^{2)}$ Despite increased public awareness and research efforts, the etiology of autism remains largely unclear. ${ }^{1}$ Research suggests that autism develops from a combination of genetic and nongenetic or environmental influences. It is believed that the underlying mechanisms of the causes of ASD are most likely polygenic, and that environmental factors, along with genetic factors, may increase the risk of ASD. ${ }^{3)}$ A review reported that there are macroscopic, microscopic, and functional abnormalities in the brains of people with autism. These numerous abnormalities indicate that etiologically, the period of causation may theoretically be in utero or early infancy. ${ }^{4}$ Evidence suggests that the risk factors for ASD are preterm birth, preeclampsia-assisted reproductive technology, and neonatal jaundice. ${ }^{5-8)}$ The relationship between small for gestational age (SGA) and ASD remains conflicting. Studies examining gestational age at birth and ASD reported different findings." ${ }^{9}$ A study in Denmark found a link between low gestational age ( $<35$ weeks) and autism, whereas studies in Canada and Egypt found no relationship between SGA and ASD. ${ }^{10,11)}$

SGA status is a distinct risk factor for birth weight or gestational age and reflects fetal growth and well-being. Larsson et al. reported an increased risk for SGA infants when adjusted for perinatal factors, but the risk did not remain statistically significant when adjusted for parental psychiatric history and socioeconomic characteristics. ${ }^{12,13)}$ A recent study in Sweden reported that a low birth weight and low gestational age were associated with ASD. ${ }^{14)}$ Low gestational age may indicate the vulnerability of the growing brain. Exposure to preterm birth,

Corresponding author: Mahdieh Seyedi, MSc. Autism Spectrum Disorders Research Center, Hamadan University of Medical Sciences, Fahmideh Street, Hamadan, Iran 凶Email: mahdiehseyedi@gmail.com, https://orcid.org/0000-0001-7149-6216

Received: 3 December, 2020, Revised: 13 January, 2021, Accepted: 16 January, 2021

This is an open-access article distributed under the terms of the Creative Commons Attribution Non-Commercial License (http://creativecommons.org/licenses/bync/4.0/) which permits unrestricted non-commercial use, distribution, and reproduction in any medium, provided the original work is properly cited.

Copyright (c) 2021 by The Korean Pediatric Society 
such as maternal and fetal inflammation, may be one of several causes of ASD ${ }^{15)}$ This study aimed to conduct a meta-analysis to determine whether SGA infants have an increased risk of developing ASD. A previous meta-analysis study of 10 articles reported a significant relationship. ${ }^{3)}$ This systematic review analyzed 16 studies that have investigated the relationship between SGA and ASD.

\section{Methods}

\section{Eligibility criteria}

The outcome of interest was ASD. The exposure of interest was SGA. Epidemiological studies, including cohort and casecontrol studies, addressing the association between SGA and the risk of ASD were included irrespective of language, date of publication, nationality, race, or age.

\section{Information sources and search}

The PubMed, Web of Science, and Scopus databases were searched from inception to November 2020 using the following search terms: (ASD or autism spectrum disorders or autism) and (SGA, small for gestational age). The reference lists of the identified studies were manually searched to identify additional studies.

\section{Study selection}

EndNote reference manager ver. X7.4 (Clarivate, Philadelphia, PA, USA) software merged the search results and removed duplicate records from the same report. Two authors independently extracted all the data, and any disagreements were resolved by discussion. We retrieved the full texts of the potentially relevant reports and examined the full papers for study compliance with the eligibility criteria.

\section{Data extraction}

We extracted data from the included studies using an electronic data collection form prepared in Stata 11 (StataCorp, College Station, TX, USA). The data collection form included the following information: first author's name, year of publication, country, language, study design (cohort, case-control), sample size, control for confounding factors (adjusted, unadjusted), risk estimates, and 95\% confidence intervals (CIs).

\section{Methodological quality}

The quality assessment was conducted using the Newcastle Ottawa Scale (NOS). ${ }^{16)}$ The NOS was developed to evaluate the quality of nonrandomized studies with its design, content, and ease of use directed to the task of incorporating quality assessments in the interpretation of meta-analytic results. A study could achieve a maximum of 9 NOS points: 4 for quality of selection, 2 for comparability, and 3 for quality of exposure (case-control or cohort study). Studies with a NOS score of 7 or higher were considered high-quality studies, while those with a NOS score of less than 7 were classified as low- to moderatequality studies based on our previous studies.

\section{Heterogeneity and reporting bias}

Heterogeneity was assessed using the chi-square test, ${ }^{17)}$ while its quantity was measured using the $I^{2}$ statistic. ${ }^{18)}$ The possibility of publication bias was explored using Egger test and visualized using a funnel plot. ${ }^{19)}$

\section{Summary measures}

We expressed the association between SGA and the risk of ASD using odds ratio (OR) and 95\% CI. Wherever reported, we used full adjusted forms of OR controlled for at least 2 or more potential confounding factors such as gestational age, maternal smoking, pregnancy-induced hypertensive disease, maternal age, parity, and mother's country of birth.

The data were analyzed, and the results were reported using a random-effects model. ${ }^{20)}$ All statistical analyses were performed at a significance level of 0.05 using Stata 11 .

\section{Results}

\section{Description of studies}

The literature search strategy was selected for the metaanalysis of SGA and the risk of ASD (Fig. 1). The literature search included 346 publications in the electronic databases published until November 2020. An additional 478 articles that were identified through the manual search of the bibliography lists. We excluded 203 duplicates identified by EndNote and 596 irrelevant references through title and abstract review. A total of 25 references were included in the full-text review. Of them, we excluded 9 full papers because they did not meet the inclusion criteria for this meta-analysis. Finally, our meta-analysis collected data from 16 articles: 9 cohort studies and 7 case-control studies with 8,752,138 participants. ${ }^{1,5,9-12,14,15,21-28)}$ All studies were published in English. Three studies reported OR (Table 1) and

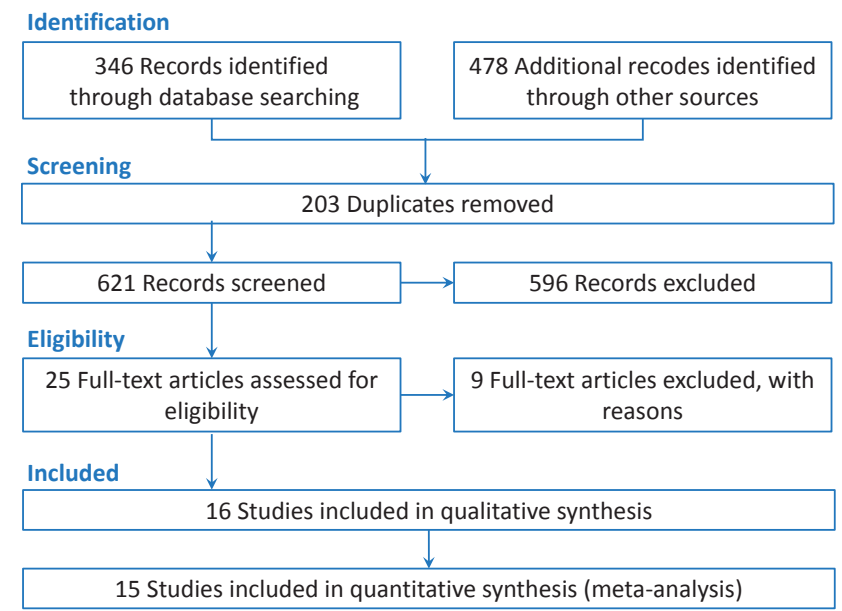

Fig. 1. Flow chart of the literature review and selection process. 
Table 1. Summary of the study's results

\begin{tabular}{|c|c|c|c|c|c|c|c|c|}
\hline Study & Country & Design & Sample & Diagnose method & Child age (yr) & Estimate & Adjustment & Quality \\
\hline Brumbaugh et al., ${ }^{5)} 2020$ & USA & Cohort & 7,876 & DSM-IV & 3 and more & $\mathrm{HR}$ & Adjusted & High \\
\hline Kuzniewicz et al., ${ }^{22)} 2014$ & USA & Cohort & $7,659,024$ & ICD-9 & $2-11$ & OR & Crude & High \\
\hline Buchmayer et al., ${ }^{14)} 2009$ & Sweden & Case-control & 7,296 & ICD-9 & $<10$ & OR & Adjusted & High \\
\hline Hultman et al., ${ }^{27)} 2002$ & Sweden & Case-control & 2,448 & ICD-9 & $<10$ & OR & Adjusted & High \\
\hline Lampi et al.,. ${ }^{12)} 2012$ & Finland & Case-control & 6,700 & ICD-10 & No data & OR & Adjusted & High \\
\hline Moore et al., ${ }^{1)} 2012$ & USA & Cohort & $5,979,605$ & ICD-9 & No data & OR & Adjusted & High \\
\hline Quinlan et al., ${ }^{23)} 2015$ & USA & Cohort & 927,003 & Medical record & $<3$ & OR & Adjusted & High \\
\hline Maimburg and Væth, ${ }^{9)} 2006$ & Denmark & Case-control & 922 & ICD-10 & $<10$ & OR & Crude & High \\
\hline Haglund and Källén, ${ }^{15)} 2011$ & Sweden & Cohort & 68,964 & ICD-10/ DSM-IV & $<7$ & OR & Crude & High \\
\hline Dodds et al.,. ${ }^{21)} 2011$ & Canada & Cohort & 129,733 & ICD-10 & $<2$ & OR & Crude & High \\
\hline Sujan et al., ${ }^{25)} 2017$ & Sweden & Cohort & $1,580,629$ & ICD-9/ICD-10 & $<2$ & OR & Adjusted & High \\
\hline Schieve et al., ${ }^{24)} 2014$ & USA & Cohort & 2,042 & Medical record & 8 & OR & Adjusted & High \\
\hline Maia et al., ${ }^{28)} 2019$ & Brazil & Case-control & 1,139 & DSM-5 & $2-15$ & OR & Adjusted & High \\
\hline Davidovitch et al., ${ }^{26)} 2020$ & USA & Case-control & 4,963 & DSM-IV & 11.6 & OR & Adjusted & High \\
\hline Kaddah et al., ${ }^{11)} 2013$ & Egypt & Case-control & 100 & M-chat & $2-2.5$ & OR & Crude & Low \\
\hline Vinet et al., ${ }^{10)} 2015$ & Canada & Cohort & 9,212 & ICD-9/ICD-10 & 3.7 & OR & Adjusted & High \\
\hline
\end{tabular}

DSM-IV, Diagnostic and Statistical Manual of Mental Disorders, 4th edition; ICD-9, International Statistical Classification of Diseases, ninth revision; ICD-10, International Statistical Classification of Diseases, 10th revision; DSM-5, Diagnostic and Statistical Manual of Mental Disorders, 5th edition; OR, odds ratio; HR, hazard ratio.

Study
ID

Fig. 2. Forest plot of the association between small for gestational age during pregnancy and the risk of autism spectrum disorders. OR, odds ratio; $\mathrm{Cl}$, confidence interval.

only 1 reported hazard ratios. ${ }^{5)}$

\section{Effects of exposure}

Fig. 2 demonstrates the association between SGA and the risk of ASD in the cohort and case-control studies. Based on the random-effects model, compared with SGA, the estimated OR of the risk of ASD was 1.17 (95\% CI, 1.09-1.24; 15 studies; $I^{2}$ $=56.4 \%)$. Therefore, there was a significant association between SGA and the risk of ASD. Brumbaugh et al. ${ }^{5)}$ reported that the risk of ASD based on relative risk among SGA was 1.64 (95\% CI,
0.75-3.56). Moore et al. ${ }^{1)}$ reported an association between SGA and the risk of ASD at gestational ages 23-43, 23-31, 32-33, $34-36,37-38,39-41$, and $\geq 42$ weeks separately. In addition, Schieve et al. ${ }^{24)}$ showed this association in birth cohorts of 1994 and 2000.

\section{Publication bias}

Publication bias was assessed using Begg test (Fig. 3). There was no evidence of publication bias $(P=0.030)$ among studies showing an association between SGA and the risk of ASD. 


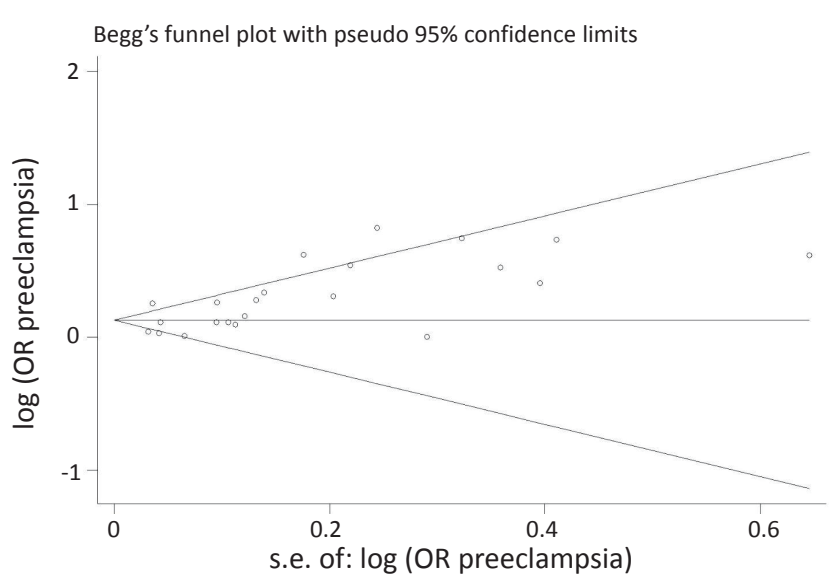

Fig. 3. Funnel plot of the association between small for gestational age during pregnasncy and the risk of autism spectrum disorders. OR, odds ratio.

Table 2. Quality of studies based on the Newcastle Ottawa Scale

\begin{tabular}{|c|c|c|c|c|}
\hline Study & Selection & Comparability & Exposure & Total \\
\hline Brumbaugh et al., 2020 & 4 & 2 & 2 & 8 \\
\hline Kuzniewicz et al., ${ }^{22)} 2014$ & 4 & 1 & 3 & 8 \\
\hline Buchmayer et al., ${ }^{14)} 2009$ & 3 & 2 & 2 & 7 \\
\hline Hultman et al., ${ }^{27)} 2002$ & 3 & 2 & 2 & 7 \\
\hline Lampi et al., ${ }^{12)} 2012$ & 3 & 2 & 2 & 7 \\
\hline Moore et al., ${ }^{1)} 2012$ & 3 & 2 & 3 & 8 \\
\hline Quinlan et al., ${ }^{23)} 2015$ & 3 & 2 & 2 & 7 \\
\hline Maimburg and Væth,' 2015 & 3 & 1 & 3 & 7 \\
\hline Haglund and Källén, ${ }^{15)} 2011$ & 3 & 1 & 3 & 7 \\
\hline Dodds et al., ${ }^{21)} 2011$ & 4 & 1 & 2 & 7 \\
\hline Sujan et al., 2017 & 3 & 2 & 2 & 7 \\
\hline Schieve et al., ${ }^{24)} 2014$ & 3 & 2 & 2 & 7 \\
\hline Maia et al., ${ }^{28)} 2019$ & 3 & 2 & 2 & 7 \\
\hline Davidovich et al., ${ }^{26)} 2020$ & 3 & 2 & 2 & 7 \\
\hline Kaddah et al., ${ }^{11)} 2013$ & 2 & 1 & 1 & 4 \\
\hline Vinet et al., 2015 & 3 & 2 & 3 & 8 \\
\hline
\end{tabular}

\section{Study quality}

According to the NOS scale, only 1 study was of low quality, while the rest of the studies were of high quality (Table 2).

\section{Subgroup analysis}

We performed a subgroup analysis based on the crude/ adjusted form and study design. We found a significant association between SGA and risk of ASD in crude and adjusted studies of 1.30 (95\% CI, 1.21-1.38) and 1.11 (95\% CI, 1.041.18), respectively. In addition, there was a significant association between SGA and risk of ASD in cohort and case-control studies of 1.14 (95\% CI, 1.06-1.21) and 1.60 (95\% CI, 1.30-1.190), respectively (Table 3 ).

\section{Discussion}

In this systematic review, we extracted the available data from
Table 3. Results of subgroup analysis of the associetion small for gestational age and the risk of autism spectrum disorders

\begin{tabular}{lccr}
\hline \multirow{2}{*}{ Variable } & \multicolumn{3}{c}{ Overweight } \\
\cline { 2 - 4 } & No. of studies & OR (95\% Cl) & \multicolumn{1}{c}{${ }^{2}$} \\
\hline Study's design & & $1.60(1.30-1.90)$ & $0.0 \%$ \\
$\quad$ Case-control & 5 & $1.14(1.06-1.21)$ & $55.5 \%$ \\
$\quad$ Cohort & 10 & $1.11(1.04-1.18)$ & $37.7 \%$ \\
Adjusted/crude form & & $1.30(1.21-1.38)$ & $0.0 \%$ \\
$\quad \begin{array}{l}\text { Adjusted form } \\
\text { Crude form }\end{array}$ & 10 & & \\
\hline OR, odds ratio; $\mathrm{Cl}$, confidence interval. & 5 &
\end{tabular}

epidemiological studies to determine the association between SGA and the risk of ASD. Our results suggest that SGA is a risk factor for ASD.

Only 1 meta-analysis to date has been conducted on the association between SGA and the risk of ASD. They showed that SGA was a risk factor for ASD risk (OR, 1.35; 95\% CI, 1.14-1.61). ${ }^{3}$ However, that meta-analysis included 10 studies published until 2007 and did not include a search of the Web of Science database.

The association between SGA and autism may reflect neurodevelopmental problems that occur in the prenatal period. In the prenatal period, the pathophysiology that limits fetal growth may also disrupt neurologic development. The main reason for intrauterine growth restriction and SGA is due to placental insufficiency, a situation in which the fetus does not reach its growth potential due to a limited transport of nutrients and oxygen. ${ }^{29)}$

Studies have reported that SGA is a marker for several risk factors before birth that may be associated with ASD, such as preeclampsia during pregnancy. ${ }^{6}$ In addition, maternal risk behaviors such as smoking, alcohol, or other substance use were associated with low birth weight, prematurity, and ASD. ${ }^{30,31)}$

This study has several limitations. To control for known risk factors of placental abruption, we used the adjusted form. However, some studies reported only the unadjusted form of OR. This might introduce information bias in our results, although we reported results based on the adjusted and unadjusted forms and found no significant difference between the results of adjusted and unadjusted studies. In addition, not all studies mentioned the participants' gestational ages at birth; therefore, we could not perform a subgroup analysis based on gestational age, which may have been a confounding factor. Despite the above limitations, the present meta-analysis could accurately estimate the association between SGA and the risk of ASD.

In conclusion, based on OR reports in epidemiological studies, we showed that SGA can increase the risk of and is a risk factor for ASD. The association between SGA and the risk of ASD has further relevance for the current public health emphasis on appropriate prepregnancy weight and pregnancy weight gain. 


\section{Footnotes}

Conflicts of interest: No potential conflict of interest relevant to this article was reported.

Acknowledgments: This study was financially supported by Hamadan university of Medical Sciences with code: 9910167 203.

\section{ORCID:}

Ensiyeh Jenabi @ https://orcid.org/0000-0002-4536-0814

Saeid Bashirian @ https://orcid.org/0000-0003-2133-087X

Zahra Asali $@$ https://orcid.org/0000-0002-8127-5000

Mahdieh Seyedi $\odot$ https://orcid.org/0000-0001-7149-6216

\section{References}

1. Moore GS, Kneitel AW, Walker CK, Gilbert WM, Xing G. Autism risk in small-and large-for-gestational-age infants. Am J Obstet Gynecol 2012; 206:314.e1-9.

2. Modabbernia A, Velthorst E, Reichenberg A. Environmental risk factors for autism: an evidence-based review of systematic reviews and metaanalyses. Mol Autism 2017;8:13.

3. Gardener H, Spiegelman D, Buka SL. Perinatal and neonatal risk factors for autism: a comprehensive meta-analysis. Pediatrics 2011;128:344-55.

4. Newschaffer CJ, Fallin D, Lee NL. Heritable and nonheritable risk factors for autism spectrum disorders. Epidemiol Rev 2002;24:137-53.

5. Brumbaugh JE, Weaver AL, Myers SM, Voigt RG, Katusic SK. Gestational age, perinatal characteristics, and autism spectrum disorder: a birth cohort study. J Pediatr 2020;220:175-83.e8.

6. Jenabi E, Karami M, Khazaei S, Bashirian S. The association between preeclampsia and autism spectrum disorders among children: a metaanalysis. Korean J Pediatr 2019;62:126-30.

7. Jenabi E, Bashirian S, Khazaei S. Association between neonatal jaundice and autism spectrum disorders among children: a meta-analysis. Clin Exp Pediatr 2020;63:8-13.

8. Jenabi E, Seyedi M, Hamzehei R, Bashirian S, Rezaei M, Razjouyan K, et al. The association between assisted reproductive technology and autism spectrum disorders in Iran: a case-control study. Clin Exp Pediatr 2020;63:368-72.

9. Maimburg RD, Væth M. Perinatal risk factors and infantile autism. Acta Psychiatr Scand 2006;114:257-64.

10. Vinet É, Pineau CA, Clarke AE, Scott S, Fombonne É, Joseph L, et al. Increased risk of autism spectrum disorders in children born to women with systemic lupus erythematosus: results from a large population-based cohort. Arthritis Rheumatol 2015;67:3201-8.

11. Kaddah FAA, Nassar JF, Ghandour HH, El-Farghali OG. Screening for autism in low-birth-weight Egyptian toddlers. Egypt J Otolaryngol 2013;29:38-45

12. Lampi KM, Lehtonen L, Tran PL, Suominen A, Lehti V, Banerjee PN, et al. Risk of autism spectrum disorders in low birth weight and small for gestational age infants. J Pediatr 2012;161:830-6.

13. Larsson HJ, Eaton WW, Madsen KM, Vestergaard M, Olesen AV, Agerbo E, et al. Risk factors for autism: perinatal factors, parental psychiatric history, and socioeconomic status. Am J Epidemiol 2005;161:916-25.

14. Buchmayer S, Johansson S, Johansson A, Hultman CM, Sparén P, Cnattingius $\mathrm{S}$. Can association between preterm birth and autism be explained by maternal or neonatal morbidity? Pediatrics 2009;124:e817-25.
15. Haglund NG, Källén KB. Risk factors for autism and Asperger syndrome: perinatal factors and migration. Autism 2011;15:163-83.

16. Joseph RM, O'Shea TM, Allred EN, Heeren T, Hirtz D, Paneth N, et al. Prevalence and associated features of autism spectrum disorder in extremely low gestational age newborns at age 10 years. Autism Res 2017;10:224-32.

17. Wells GA, Shea B, O'Connell D, Peterson J, Welch V, Losos M, et al. The Newcastle-Ottawa Scale (NOS) for assessing the quality of nonrandomised studies in meta-analyses [Internet]. Ottawa (ON): Ottawa Hospital Research Institute; 2009 [cited 2020 Nov 5]. Available from: http://www.ohri.ca/programs/clinical_epidemiology/oxford.asp.

18. Higgins JPT, Green S. Cochrane handbook for systematic reviews of interventions Version 5.0.0 [Internet]. London: The Cochrane Collaboration; 2008 [updated 2008 Feb; cited 2020 Nov 5]. Available from: www.cochrane-handbook.org.

19. Higgins JPT, Thompson SG, Deeks JJ, Altman D. Measuring inconsistency in meta-analyses. BMJ 2003;327:557-60.

20. Egger M, Davey SG, Schneider M, Minder C. Bias in meta-analysis detected by a simple, graphical test. BMJ 1997;315:629-34.

21. Dodds L, Fell DB, Shea S, Armson BA, Allen AC, Bryson S. The role of prenatal, obstetric and neonatal factors in the development of autism. Rev J Autism Dev Disord 2011;41:891-902.

22. Kuzniewicz MW, Wi S, Qian Y, Walsh EM, Armstrong MA, Croen LA. Prevalence and neonatal factors associated with autism spectrum disorders in preterm infants. J Pediatr 2014;164:20-5.

23. Quinlan CA, McVeigh KH, Driver CR, Govind P, Karpati A. Parental age and autism spectrum disorders among New York city children 0-36 months of age. Matern Child Health J 2015;19:1783-90.

24. Schieve LA, Tian LH, Baio J, Rankin K, Rosenberg D, Wiggins L, et al. Population attributable fractions for three perinatal risk factors for autism spectrum disorders, 2002 and 2008 autism and developmental disabilities monitoring network. Ann Epidemiol 2014;24:260-6.

25. Sujan AC, Rickert ME, Öberg AS, Quinn PD, Hernández-Díaz S, Almqvist $\mathrm{C}$, et al. Associations of maternal antidepressant use during the first trimester of pregnancy with preterm birth, small for gestational age, autism spectrum disorder, and attention-deficit/hyperactivity disorder in offspring. JAMA 2017;317:1553-62.

26. Davidovitch M, Kuint J, Lerner-Geva L, Zaslavsky-Paltiel I, Rotem RS, Chodick G, et al. Postnatal steroid therapy is associated with autism spectrum disorder in children and adolescents of very low birth weight infants. Pediatr Res 2020;87:1045-51.

27. Hultman CM, Sparén P, Cnattingius S. Perinatal risk factors for infantile autism. Epidemiology 2002;13:417-23.

28. Maia FA, Oliveira LMM, Almeida MTC, Alves MR, Saeger VSdA, Silva VBd, et al. Autism spectrum disorder and postnatal factors: a case-control study in brazil. Rev Paul Pediatr 2019;37:398-405.

29. Hussain K, Dunne MJ. Hypoglycemia. In: Brook CGD, Clayton PE, Brown RS. Brook's clinical pediatric endocrinology. Malden (MA): Blackwell Pub; 2005. p. 474.

30. Ekblad M, Gissler M, Lehtonen L, Korkeila J. Prenatal smoking exposure and the risk of psychiatric morbidity into young adulthood. Arch Gen Psychiatry 2010;67:841-9.

31. Kelly RH, Russo J, Holt VL, Danielsen BH, Zatzick DF, Walker E, et al. Psychiatric and substance use disorders as risk factors for low birth weight and preterm delivery. Obstet Gynaecol 2002;100:297-304.

How to cite this article: Jenabi E, Bashirian S, Asali Z, Seyedi M. Association between small for gestational age and risk of autism spectrum disorders: a meta-analysis. Clin Exp Pediatr 2021;63:538-42. https://doi.org/10.3345/cep.2020.01956 